\title{
Comparing Ebola virus disease and antimicrobial resistance outbreaks in Nigeria- a cross sectional survey of awareness level of health care workers and members of community
}

\author{
I Yusuf ${ }^{1,2^{*}}, \mathrm{AH}$ Arzai $^{2}, \mathrm{M}$ Yushau², L Garba ${ }^{1}$ \\ From 3rd International Conference on Prevention and Infection Control (ICPIC 2015) \\ Geneva, Switzerland. 16-19 June 2015
}

\section{Introduction}

Ebola virus disease (EVD) outbreak in Nigeria has raised the level of awareness of both health care workers (HCWs) and members of community (MCs) on the threat posed by infectious diseases and need for improvement on infection control practices, but awareness of dangers of increasing antimicrobial resistance (AMR) remained low.

\section{Objectives}

To compare awareness level of HCWs and MCs on dangers of EVD and AMR and their control and to give educational intervention on dangers of AMR and its control to MCs with no prior knowledge of AMR.

\section{Methods}

A cross-sectional survey of $195 \mathrm{HCW}$ and 265 MCs was conducted through structured questionnaire and interview.

\section{Results}

Majority of HCWs (95.4\%) and MCs (82.8\%) have recent knowledge of EVD dangers and give reasons like EVD way of killing, stigmatization, no drugs and vaccines as reason for their awareness. Only $17.2 \%$ of MCs were aware of AMR as problem, and only $3.4 \%$ of MCs and $10.3 \%$ of HCWs agreed that AMR is more deadly than EVD. However, 76.4\% Drs, $95.1 \%$ nurses, $67.9 \%$ lab scientist, $66.7 \%$ pharmacists, $77.4 \%$ students and $100 \%$ of civil servants, drivers and religious leaders believed that EVD is more horrific and spread faster, while in reality its dangers is a drop in the ocean when compared with AMR. They both

${ }^{1}$ Microbiology (Biotechnology and Bio-molecular Sciences), Universiti Putra Malaysia, Selangor, Kuala Lumpur, Malaysia

Full list of author information is available at the end of the article attributed the rapid awareness of EVD in Nigeria despite being new, to seriousness with which stakeholders and media fight EVD, the gesture AMR is yet to receive. All agreed that prevention, not treatment is the best option to tackle EVD. About $84.1 \%$ of HCWs and only $17.2 \% \mathrm{MCs}$ believed that careful use of antibiotics can reduce cases of AMR. After short briefing of some MCs on dangers of AMR and its control through prudent use of antibiotics, a shift in belief from $17.2 \%$ to $48.7 \%$ was observed, with $64.8 \%$ civil servants, $54.1 \%$ students, $18.2 \%$ drivers $25.5 \%$ villagers and $25.0 \%$ traditional healers changed their method of control option to prevention rather than treatment.

\section{Conclusion}

Despite extreme panic over EVD, awareness on dangers of AMR and its control remained very low among MCs. Efforts put in place during EVD outbreak by all stakeholders and the media need to be double to increase the knowledge of both HCWs and MCs toward AMR.

\section{Disclosure of interest}

None declared.

\section{Authors' details}

'Microbiology (Biotechnology and Bio-molecular Sciences), Universiti Putra Malaysia, Selangor, Kuala Lumpur, Malaysia. ${ }^{2}$ Microbiology, Bayero University Kano, Nigeria, Kano, Nigeria.

Published: 16 June 2015

\section{doi:10.1186/2047-2994-4-S1-P1}

Cite this article as: Yusuf et al:: Comparing Ebola virus disease and antimicrobial resistance outbreaks in Nigeria- a cross sectional survey of awareness level of health care workers and members of community. Antimicrobial Resistance and Infection Control 2015 4(Suppl 1):P1. 